\title{
Role of Voltage-Dependent Calcium Channel Long-Term Potentiation (LTP) and NMDA LTP in Spatial Memory
}

\author{
Albert M. Borroni, ${ }^{1}$ Harlan Fichtenholtz, ${ }^{2}$ Brian L. Woodside, ${ }^{3}$ and Timothy J. Teyler ${ }^{3}$ \\ ${ }^{1}$ Neuroscience Program, Oberlin College, Oberlin, Ohio 44074, ${ }^{2}$ Center for Cognitive Neuroscience, Duke University, \\ Durham, North Carolina 27708, and 3Northeastern Ohio College of Medicine, Rootstown, Ohio 44272
}

\begin{abstract}
This experiment explores the role of two forms of long-term potentiation (LTP) in behavioral memory. NMDA and/or voltagedependent calcium channels (VDCCs) were antagonized pharmacologically at levels that block nmdaLTP and vdccLTP, respectively, in rats learning an eight-arm radial maze task. Animals were trained twice a day for $11 \mathrm{~d}$ under the systemic influence of MK-801, verapamil, both drugs, or saline. During acquisition, the mixed drug group displayed significantly more working memory errors and reference memory errors than all other groups. The mixed drug group was markedly impaired on the first daily trial but improved dramatically on their second daily trial. After a $7 \mathrm{~d}$
\end{abstract}

delay, saline and MK-801 animals maintained their predelay level of performance. The performance of the verapamil groups declined significantly over the delay. These results demonstrate that: (1) vdccLTP is necessary for the retention of information over a $7 \mathrm{~d}$ period, (2) the blockade of both forms of LTP prevents the retention of information over a $21 \mathrm{hr}$ period, and (3) blockade of both forms of LTP does not prevent the storing of information over a short period of time (3 hr).

Key words: long-term potentiation; nmdaLTP; vdccLTP; spatial memory; learning; voltage-dependent calcium channel; verapamil; MK-801; NMDA
The role of long-term potentiation (LTP) as a synaptic substrate of memory in behaving animals is controversial (Shors and Matzel, 1997). Some of the controversy may relate to the prevalence of different induction mechanisms and thus incomplete blockage of LTP present in the awake rodent. To address this question, we have selectively and independently blocked the two major forms of LTP in the mammalian forebrain during the acquisition an eight-arm spatial maze task. Successful mastery of the radial maze is dependent on having a functional hippocampus and the ability to use spatial cues (Jarrard, 1993). LTP, which is thought to be involved in the development of spatial maps used by the animal, can be induced by various patterns of synaptic activity. Low-frequency activity $(25-50 \mathrm{~Hz})$ produces a well studied form of LTP (Bliss and Collingridge, 1993) that is completely blocked by antagonism of NMDA channels (nmdaLTP). Higher-frequency activity (100-200 $\mathrm{Hz}$ ) also induces LTP, but the LTP produced by this pattern of activity is only partially blocked by NMDA antagonists; the residual LTP is blocked by antagonizing L-type voltage-dependent calcium channels (VDCCs) and is referred to as vdccLTP (Grover and Teyler, 1990; Grover, 1998).

The two forms of LTP appear to reflect the activation of different cellular mechanisms. VdccLTP is blocked by the application of tyrosine kinase inhibitors, whereas nmdaLTP is unaffected. Conversely, serine-threonine kinase inhibitors have no effect on vdccLTP but block nmdaLTP completely (Cavus and Teyler, 1996). Also, these two forms of LTP have different kinetics, with nmdaLTP having a fast onset and slow decay and vdccLTP having a slow onset and decay. The different phosphorylation cascades initiated in the two forms of LTP result in differential regulation of synaptic function (Stricker et al., 1999) and gene expression (Bading et al., 1993; Ghosh and Greenberg, 1995). Taken together, these findings suggest that the two forms of LTP serve two different functions (Cavus and Teyler, 1996): (1) the formation of short- or

\footnotetext{
Received Feb. 22, 2000; revised Sept. 25, 2000; accepted Sept. 27, 2000.

This work was supported by National Institutes of Health Grant MH57892. We thank the Oberlin College Winter Term committee, the Oberlin College Winter Term 1999 students for training and caring for the rats, and L. Jarrard and L. Brown-Croyts for critically reading this manuscript.

Correspondence should be addressed to Dr. Albert Borroni, Neuroscience Program, 130 West Lorain Street, Oberlin College, Oberlin, OH 44074. E-mail: Albert.Borroni@oberlin.edu.

Copyright (C) 2000 Society for Neuroscience $0270-6474 / 00 / 209272-05 \$ 15.00 / 0$
}

intermediate-term memories by activation of NMDA receptors and (2) the formation of longer-lasting memories by the activation of VDCCs.

In this experiment, we tested the effect of selectively blocking the channels responsible for the induction of nmdaLTP and vdccLTP on the ability of rats to learn and retain information needed to navigate the eight-arm radial maze (Olton and Papas, 1979). Blockade of nmdaLTP with the NMDA receptor blocker MK-801 has been shown to disrupt working memory (WM) and reference memory (RM) in the radial arm maze (Shapiro and Caramanos, 1990). However, the effects of blocking vdccLTP with the VDCC blocker verapamil have never been assessed in this or any behavioral learning task. Our results indicate that animals given verapamil either by itself or mixed with MK-801 were impaired in their ability to navigate the maze after a delay of $7 \mathrm{~d}$ (i.e., they had an increased number of errors after the delay). Also, animals treated with both verapamil and MK-801 showed impaired performance on the first but not the second trial of each day.

\section{MATERIALS AND METHODS}

Animals. Thirty-two male Sprague Dawley rats obtained from Hilltop Lab Animals (Scottsdale, PA) were used in this experiment. The rats were between $250 \mathrm{gm}$ and $450 \mathrm{gm}$ pretraining weight, were between 60- and 80 -d-old, and were naive to the radial arm maze task. Each animal was housed individually in an opaque plastic cage $(35 \times 21 \times 20 \mathrm{~cm})$. All of the cages were kept on a movable rack that was moved from the vivarium to the experiment room in the morning and returned to the vivarium at the end of the day. Rats had access to water ad libitum and had food restricted to keep them at $85 \%$ of their pretraining weight.

Drugs. NmdaLTP was blocked by systemic injection of the NMDA receptor antagonist MK-801 $(0.1 \mathrm{mg} / \mathrm{kg})$. VdccLTP was blocked by systemic injection of the L-type calcium channel blocker verapamil (10 $\mathrm{mg} / \mathrm{kg}$ ). The group in which both forms of LTP were blocked received both drugs at the above concentrations. These drugs and concentrations were effective in blocking tetanus-induced LTP in vivo (Morgan and Teyler, 1999). Drugs were diluted in $0.9 \%$ saline vehicle so that the injected volume was $1 \mathrm{ml} / 1 \mathrm{~kg}$. Control animals received injections of $0.9 \%$ saline. The rats were injected $30-90 \mathrm{~min}$ before the first daily trial. Systemic administration of drugs was used to ensure drug delivery to all relevant CNS sites, given that both forms of LTP under study are found in widespread areas of the forebrain. Verapamil and MK-801 were obtained from Research Biochemicals International (Natick, MA).

Apparatus. Two identical eight-arm radial mazes located in separate but similar rooms were used in this experiment. Both rooms measured $\sim 2.5 \times 2.5 \mathrm{~m}$ and contained multiple similar external stimuli (posters, counter top, cabinets). The center of the maze was a platform with a diameter of $25 \mathrm{~cm}$. Each arm extended $72 \mathrm{~cm}$ from the center and was 


\section{BAITS EATEN}

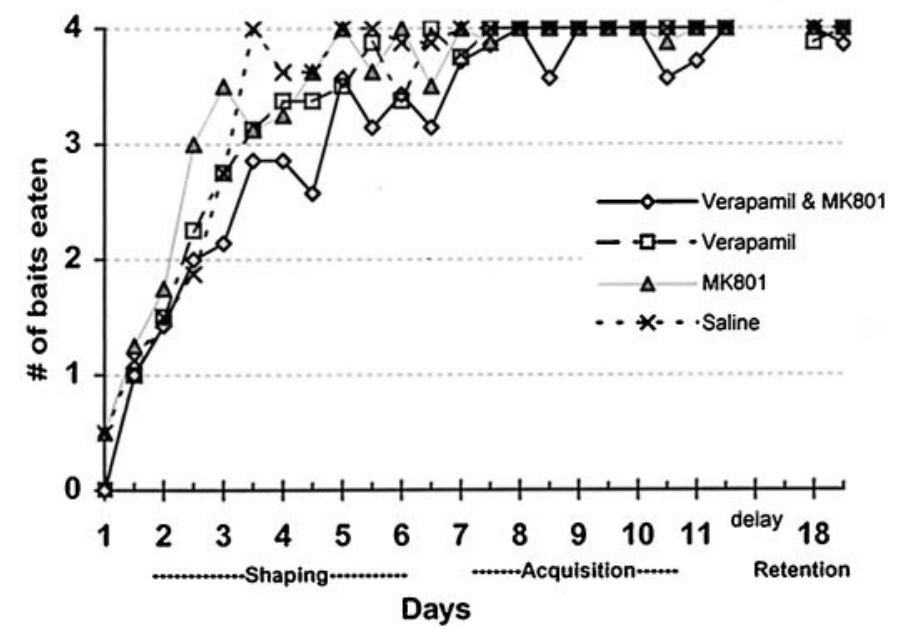

Figure 1. Baits eaten. Group average baits eaten per trial across shaping (days 1-6), acquisition (days 7-11), and retention (day 18). Trials were terminated after eating four baits or $10 \mathrm{~min}$. Animals were given one of four treatments: mixed drug (blocked both vdccLTP and nmdaLTP with10 $\mathrm{mg} / \mathrm{kg}$ verapamil and $0.1 \mathrm{mg} / \mathrm{kg} \mathrm{MK}-801$, respectively) $(\diamond)$, verapamil (blocked vdccLTP with10 mg/kg verapamil) ( $\square$ ), MK-801 (blocked nmdaLTP with $0.1 \mathrm{mg} / \mathrm{kg}$ MK-801) $(\triangle)$, and saline (control; 0.9\%) $(X)$. Treatments were administered intraperitoneally $15-30 \mathrm{~min}$ before the first trial (trial 1) of each day. Error bars have been omitted for clarity.

7.5-cm-wide. The sides of the arms were clear plastic, and each arm had a recessed food cup (2-cm-deep $\times 3$-cm-across) $4 \mathrm{~cm}$ from the end of the arm. The maze was $50 \mathrm{~cm}$ above the ground and almost completely filled the experiment rooms. The rats run in each maze were balanced across treatment groups, and each rat was run on only one maze. A $t$ test of RM errors (RMEs) across trials indicated that there was no "room effect" ( $p=$ $0.29)$.

Procedure. The rats were randomly assigned to one of the two mazes and one of four treatments ( $n=8$ rats per group): (1) mixed drug (verapamil and MK-801) (blocks both nmdaLTP and vdccLTP), (2) verapamil (blocks vdccLTP), (3) MK-801 (blocks nmdaLTP), or (4) saline (control). RMEs were scored by counting the number of nonbaited arms the animal entered on each trial (maximum of four). WM errors (WMEs) were assessed by counting the number of times on each trial rats re-entered an arm from which they had already eaten.

All animals were housed on a large moveable rack. Each day the rack was rolled into the testing room. Each animal was given two trials per day, separated by $3 \mathrm{hr}$. Each trial was started by giving the animal an appropriate injection based on their group assignment. Injections were made intraperitoneally. At 30 min after injection, the animals were handled for $30 \mathrm{sec}$, placed in the center of the maze, and allowed to move freely for 10 min or until they found all four baits. Each of the four arms was baited with one-half of a Froot Loop (Kellogg's Cereal, Battle Creek, MI). The specific arms that were baited for a given rat were randomly determined and then kept constant throughout training and testing. The experimenter sat in the doorway and recorded the trials. Records were kept of entries into baited arms, entries into unbaited arms, number of baits found, and the time to complete the task. An arm was considered to be entered when all four paws were in the arm. After each trial, the maze was wiped clean with water and rotated clockwise $45^{\circ}$. At the end of the day, all animals were taken back to the vivarium.

Animals were not initially "shaped" with food present in all arms to avoid them having to learn a different strategy during the experiment proper (e.g., food present at four of eight arms). Throughout all trials, food was present only in the four arms randomly chosen for each animal.

Training was divided into three stages: shaping, acquisition, and retention. The shaping stage was ended when, on average, 3.5 baits were eaten by the group at large on both daily trials (see Fig. 1). Subsequent trials are designated as having occurred during the acquisition stage. Animals were given $5 \mathrm{~d}$ of trials during the acquisition stage, at which point training was stopped.

One week after the last day of acquisition, the animals were given two more retention trials in the maze, thus dividing the training into a shaping phase, an acquisition phase, and a retention phase. During the week between acquisition and retention, the animals were kept in the vivarium without drugs. The day before the retention test, the caged animals were taken back into the testing room as a contextual reminder stimulus, but they were not placed in the maze or injected.

\begin{tabular}{llll}
\hline Table 1. Activity levels & & \\
& $\begin{array}{l}\text { All days } \\
\text { (both trials) }^{a}\end{array}$ & $\begin{array}{l}\text { Acquisition days } \\
\text { (both trials) }^{b}\end{array}$ & $\begin{array}{l}\text { Acquisition days } \\
\text { (trial } 1 \text { only) }^{c}\end{array}$ \\
\hline Saline & $0.063 \pm 0.007$ & $0.860 \pm 0.008$ & $0.800 \pm 0.007$ \\
Mixed drug & $0.056 \pm 0.008$ & $0.671 \pm 0.008$ & $0.685 \pm 0.007$ \\
MK-801 & $0.066 \pm 0.007$ & $0.846 \pm 0.008$ & $0.818 \pm 0.007$ \\
Verapamil & $0.045 \pm 0.007$ & $0.650 \pm 0.008$ & $0.571 \pm 0.007$
\end{tabular}

The activity of each animal was measured by counting the number of arms entered per second. Values shown are means \pm SD.

${ }^{a}$ Group results are tabulated here for all $11 \mathrm{~d}$ of the experiment (both daily trials).

${ }^{b}$ Group results are tabulated here for acquisition trials 7-11 (both daily trials).

${ }^{c}$ Group results are tabulated here for acquisition trials 7-11 (only the first daily trial).

\section{RESULTS}

Animals were run in the maze twice a day. Subsequently, the first trial of each day will be referred to as trial 1 , while the second one, which occurred $3 \mathrm{hr}$ after the first, is referred to as trial 2. All groups received $6 \mathrm{~d}$ of shaping followed immediately by $5 \mathrm{~d}$ of acquisition. After $5 \mathrm{~d}$ of acquisition, all animals except one (from the mixed drug group) were consistently obtaining all four Froot Loops (Fig. 1). This animal was eliminated from the study for continually attempting to climb over the maze walls and failing to finish the task within the 10 min cutoff. He is included in the Figure 1 graph but not in any subsequent graphs or analysis.

\section{Activity}

Visual observation of all animals in their home cages revealed no drug-induced behavioral abnormalities, and no animals were removed for this reason. To assess any potentially confounding effects of drug administration on activity, we measured the average number of arms entered per second. An ANOVA across all $11 \mathrm{~d}$ and both daily trials reveals that there is a significant change in activity across days $\left(F_{(10,17)}=21.577 ; p<0.0001\right)$ and trials $\left(F_{(1,26)}=\right.$ $7.440 ; p<0.011)$. There is a significant interaction between trial and drug group $\left(F_{(3,27)}=4.228 ; p<0.015\right)$, and between days and trials $\left(F_{(10,17)}=2.771 ; p<0.031\right)$. There is no interaction between trials and days and drug groups $\left(F_{(30,57)}=0.630 ; p<0.914\right)$ or between days and drug group $\left(F_{(30,57)}=1.089 ; p<0.383\right)$. The main effect of drugs was not significant $(F=262.35 ; p>0.138)$. A pairwise comparison of group means and a two-sided Dunnet's test for multiple comparisons to a control revealed that the activity levels of all the groups were not significantly different from the control, but that the activity levels between the verapamil and MK-801 groups were different at a 0.05 level. See Table 1 for descriptive statistics for each drug group.

The ANOVA testing activity levels across acquisition days rather than all $11 \mathrm{~d}$ show a similar pattern, except that interaction between trial and drug group $\left(F_{(3,27)}=2.177 ; p<0.114\right)$ and between days and trial $\left(F_{(4,24)}=0.464 ; p<0.464\right)$ are no longer significant, suggesting that there is no longer an interaction between trial and drug group or between days and trials over the last $5 \mathrm{~d}$ of training. Pairwise comparisons of activity among drug groups reveal that all groups are exhibiting the same level of activity. This is also true when evaluating data from only trial 1 . See Table 1 for descriptive statistics for different drug groups.

Because Caramanos and Shapiro (1994) have described increased activity after MK-801 administration, we tested independent groups of animals receiving the same drugs and dosages in an open-field activity device. The groups ( $n=4$ animals per group) receiving MK-801 displayed significantly more light-beam crossings $30 \mathrm{~min}(p>0.01)$ and $120 \mathrm{~min}(p>0.05)$ after injection compared with animals receiving saline. The verapamil group did not differ from saline controls. The effect of giving both drugs to an animal was not tested in this manner. 


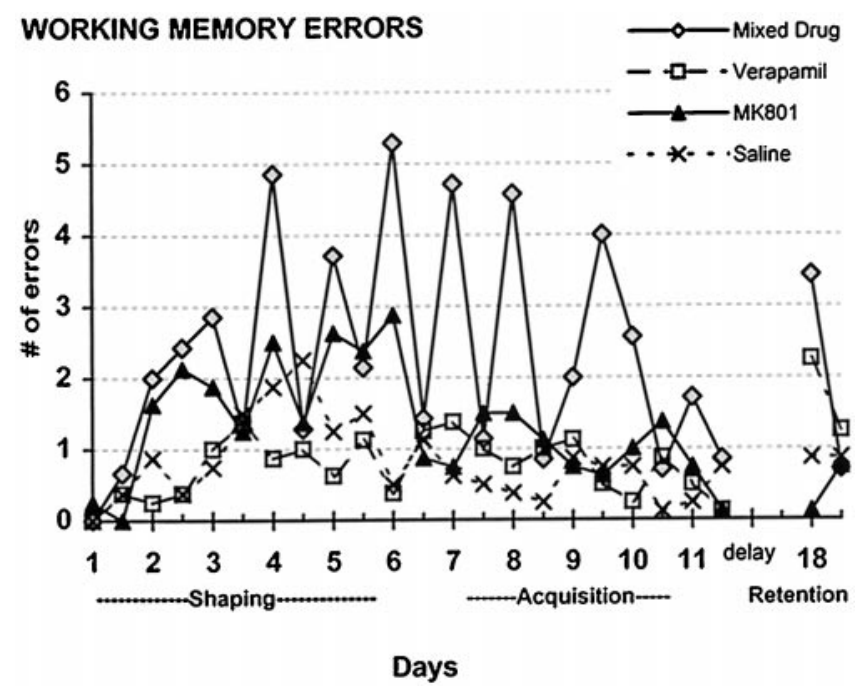

Figure 2. WMEs across shaping, acquisition, and retention trials. Each point is the average number of WMEs recorded on the first and on the second trials of each day by the four treatment groups. During shaping, the animals are learning which arms are baited and consequently do not enter all of the arms in the allotted $10 \mathrm{~min}$. Because a WME occurs only with repeat arm entries, this measure is low during early shaping trials. During acquisition, the number of WMEs remains relatively constant for all but the group receiving blockade of both forms of LTP (mixed drug group). The mixed drug group (nmdaLTP and vdccLTP blocked) displays a dramatic scalloping, showing high levels of WMEs on the first daily trial and more normal levels on the second daily trial, which occurred $3 \mathrm{hr}$ later. In the retention test, only the group receiving verapamil (to block vdccLTP) showed significant forgetting. The scalloped performance of the mixed drug group was still seen during retention tests. Error bars have been omitted for clarity.

\section{WMEs: acquisition}

A graph of WMEs (the number of baited arms that the rat reenters during the trial) across days 1-11 is shown in Figure 2. Error bars are omitted for clarity but are included on Figure 3.

An ANOVA over acquisition trials (days 7-11) finds a significant difference in WMEs across trials $\left(F_{(1,27)}=8.313 ; p<0.008\right)$ and between trial and drug group $\left(F_{(3,27)}=5.667 ; p<0.004\right)$, but not across days $\left(F_{(4,24)}=1.744 ; p<0.173\right)$ or between trials and days $\left(F_{(4.24)}=1.034 ; p<0.410\right)$. Thus, once the animals begin eating all the baits, the number of WMEs does not change. ( $F$ values for days and between trials and days were not significant.)

The significant difference in trial and between trial and drug group over acquisition days indicates that there was a difference in performance between the first and second daily trial. This is reflected in the "scalloped" pattern demonstrated by the mixed drug group. In this group, more WMEs were evident on the first daily trial compared with the second trial of the day that occurred $3 \mathrm{hr}$ later (Fig. $3 A ; p<0.05$, Student's $t$ test). No other group displays this scalloped pattern, nor did any other group show a significant difference in errors between trial 1 and trial $2(p>0.1)$.

As illustrated by the ANOVA, during acquisition, most groups learned to an asymptotic level. However, this does not mean that the levels were equivalent. The $F$ value for between-subjects effects across drug groups was significant $\left(F_{(3)}=11.411 ; p<0.0001\right)$. Post-hoc multiple comparison tests demonstrated that the WMEs produced by the mixed drug group were significantly higher than those made by animals in the saline $(p<0.001)$, verapamil $(p<$ $0.004)$, and MK-801 $(p<0.015)$ groups. This pattern was even more pronounced when only trial 1 data were analyzed.

\section{WMEs: retention}

After the last acquisition trial, a 7 d delay was introduced before the retention trial on day 18 . Retention was assessed by comparing WMEs committed on trial 1 between day 11 and day 18. An ANOVA for WMEs across the delay was significant for days $\left(F_{(1,28)}=6.209 ; p<0.05\right)$ and for drug group $\left(F_{(3,28)}=2.956 ; p<\right.$

\section{A WORKING MEMORY - Acquisition}

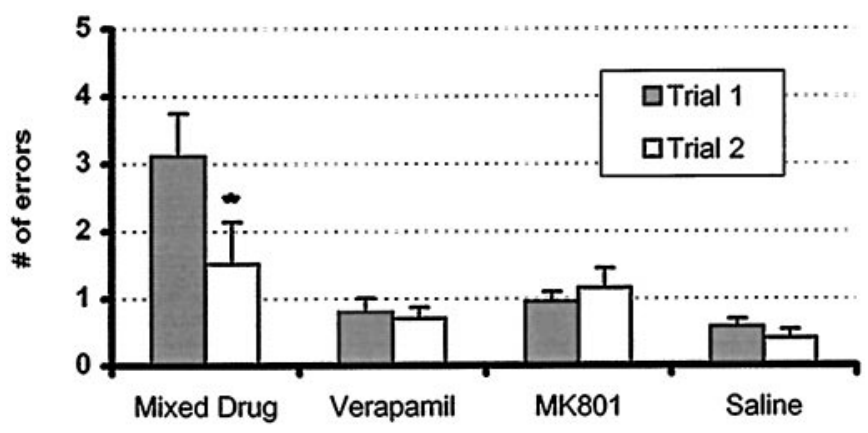

\section{B WORKING MEMORY - Retention}

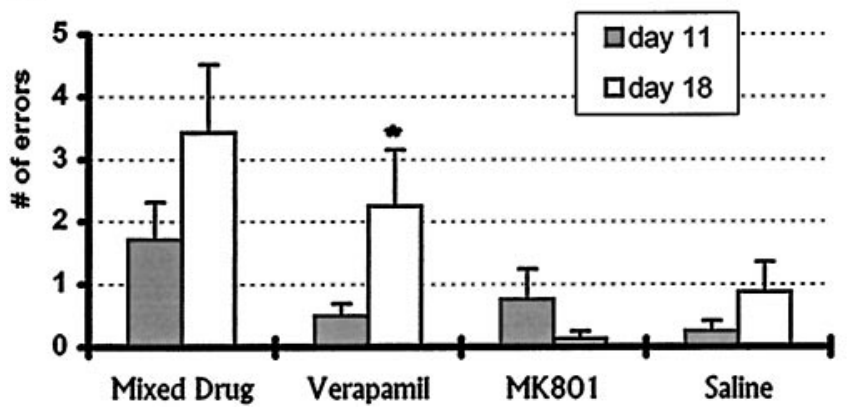

Figure 3. A, WMEs during acquisition. Only the group receiving blockade of both forms of LTP (mixed drug group) had elevated WMEs limited to the first daily trial $\left({ }^{*} p<0.05\right)$, thus producing the scalloping effect seen in Figure 2. These results suggest that blockade of both forms of LTP does not prevent the storing of information over a short period of time (the $3 \mathrm{hr}$ between trial 1 and trial 2), but that it disrupts storage over a $21 \mathrm{hr}$ period (between the last daily trial and the first trial on the following day). $B$, WMEs at retention. Across the retention interval, significant increases in WMEs on trial 1 were only seen for the verapamil group $\left({ }^{*} p<0.04\right)$. The mixed drug group showed a similar trend, but this difference was not significant. The saline and MK-801 groups retained their performance across the delay interval. These results suggest that vdccLTP is necessary for the retention of the rules supporting WM performance across a $7 \mathrm{~d}$ interval in this task.

$0.05)$. Only the verapamil group demonstrated a significant difference in WMEs (Fig. $3 B$ : trial 1, day 11, 0.50; trial 1, day 18, 2.25; $p<0.04$, Student's $t$ test). The MK-801 and saline groups did not show a significant change in performance across the delay period (i.e., they retained their level of performance across the $7 \mathrm{~d}$ retention delay) $(p>0.10)$. The mixed drug group learned poorly during training and did even worse on the retention test, although the difference was not significant.

\section{RMEs: acquisition}

A graph of RMEs (the number of unbaited arms that the rat entered during the trial) across days 1-11 is shown in Figure 4. Error bars are omitted for clarity but are included on Figure 5.

An ANOVA across acquisition trials (days 7-11) shows a significant difference in RMEs across days $\left(F_{(4,24)}=6.548 ; p<0.001\right)$ and between trials and days $\left(F_{(4,24)}=5.199 ; p<0.004\right)$. Trials $\left(F_{(1,27)}=0.665 ; p<0.422\right)$, days and drug group $\left(F_{(30,60)}=0.853\right.$; $p<0.597)$, and trials and drug group $\left(F_{(3,27)}=1.607 ; p<0.211\right)$ are not significantly different. The analysis done across acquisition trials demonstrates that the number of RMEs decreases for all groups (significant $F$ values for days and for trials and days). The scalloped pattern demonstrated in Figure 2 when measuring WMEs produced by the mixed drug group is also evident (Fig. 4) and is significant when measuring RMEs (Fig. 5).

Pairwise comparisons of the RMEs committed during trial 1 of each acquisition day shows a significant difference between the saline group and the mixed drug group $(p<0.005)$, as well as between the mixed drug group and the verapamil group ( $p<$ $0.005)$. All other comparisons were not significant $(p>0.10)$. 


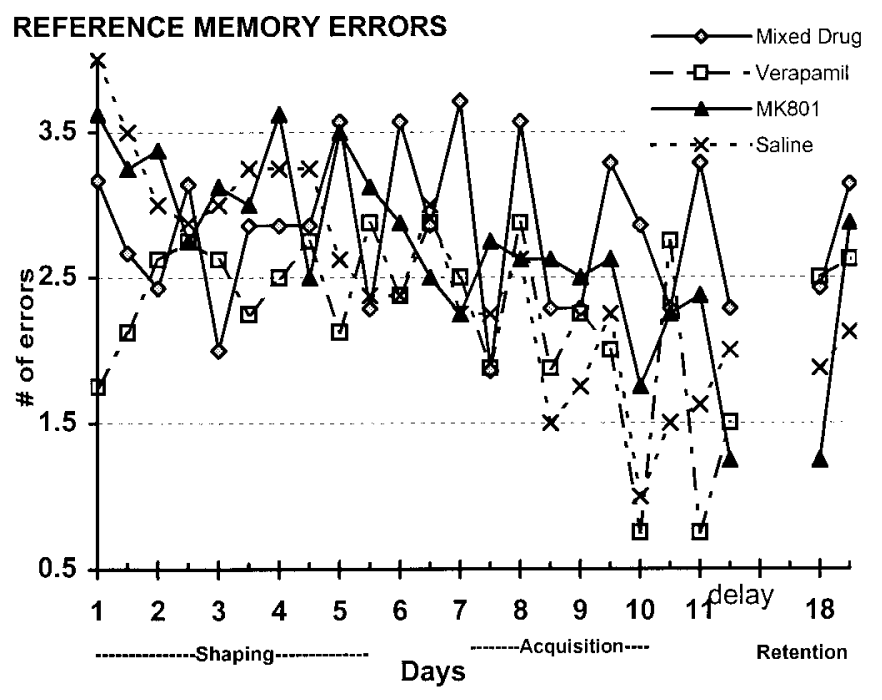

Figure 4. RMEs across shaping, acquisition, and retention trials. Each point is the average number of RMEs recorded on the first and on the second trials of each day. RMEs declined overall across acquisition trials, with the saline and verapamil groups showing the fewest errors. The mixed drug group displayed more RMEs on the first daily trial as compared with the second trial throughout acquisition. Only the verapamil group showed a significantly increased number of RMEs at retention. Error bars have been omitted for clarity.
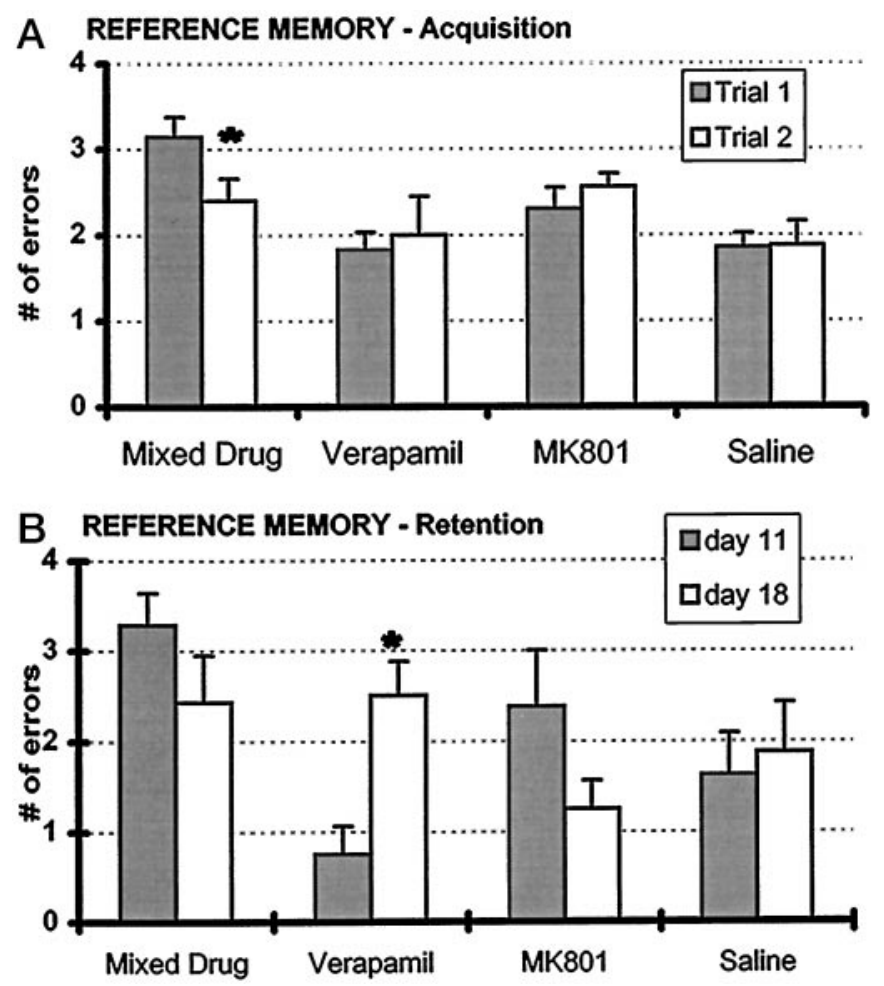

Figure 5. A, RMEs during acquisition. The elevated RMEs of the mixed drug group were limited to the first trial of the day $(* p<0.05)$. These results suggest that blocking both forms of LTP interferes with the retention of RM over a $21 \mathrm{hr}$ period from day to day, but not with retention over the $3 \mathrm{hr}$ between trial 1 and trial 2 within a day. $B$, RMEs at retention. Only the verapamil group significantly increased RMEs across the $7 \mathrm{~d}$ retention delay $(* p<0.001)$. Comparisons were made on data from trial 1 .

\section{RMEs: retention}

RMEs made on trial 1 were compared between day 11 and day 18 . An ANOVA for RMEs across the delay was significant for drug group $\left(F_{(3,28)}=2.965 ; p<0.05\right)$. Only the verapamil group showed a significantly increased number of RMEs at retention (Fig. $5 B$, trial 1, day 11, 0.55; trial 1, day 18, 2.20; $p<0.001$, Student's $t$ test). The MK-801, saline, and mixed drug groups did not show a significant change in performance across the delay period $(p>$ $0.10)$. The mixed drug group displayed high RMEs at the end of acquisition and at the retention test.

\section{DISCUSSION}

Grover and Teyler (1990) predicted that the induction of vdccLTP would be critical for the formation of long-term memories (LTMs). The results from this study support this prediction in that, after a break of $7 \mathrm{~d}$, animals treated with saline or MK-801 maintained the same level of performance, whereas animals treated with verapamil demonstrated an increase in the number of WMEs and RMEs after the same $7 \mathrm{~d}$ break. This indicates that retention of information necessary to successfully navigate the eight-arm radial maze over a long interval $(7 \mathrm{~d})$ requires the activation of VDCCdependent and not NMDA-dependent mechanisms. This of course does not mean that NMDA receptors are not involved in the induction of LTM; but it does suggest that their role might be to support or enhance the activation of VDCCs that are ultimately responsible for the biochemical cascades necessary for the induction of changes required to support LTMs. Fox and Daw (1993) have made a similar proposal for the role of NMDA receptor activation in the induction of plastic changes in the neocortex.

Interestingly, after a $7 \mathrm{~d}$ delay, animals given both drugs showed a predictable increase in the number of WMEs but a decrease in the number of RMEs (comparison of trial 1 data). In neither case was the change significant, and because these animals performed poorly even before the break, we are hesitant to make any strong claims about the effect of combining verapamil and MK-801 on long-term (7 d) retention.

However, because we used a paradigm in which animals were run on the task twice a day, on any given day we were able to observe that animals in the mixed drug group showed a marked improvement in performance between trial 1 and trial 2. The difference was significant and consistent. No other groups showed this type of behavior. There are several possible explanations for this unexpected result. First, given together, these drugs may have side effects that interfered with performance of the task in a timedependent manner. An analysis of activity levels during training indicated that the mixed drug group was not significantly more active than the other groups. Also, the activity level of the animals in the mixed drug group during trial 1 (when they made many errors) was not different from the activity level measured during trial 2 for the same group. Differences in activity level may still explain the inconsistencies between trials if there were a systemic drug effect on activity, which was not detected by the measures we used. Second, the drugs may not have blocked both forms of LTP in all relevant brain areas, thus allowing a residual amount of vdccLTP and/or nmdaLTP to sustain memory over a short interval $(<3 \mathrm{hr})$ but not the longer interval of $21 \mathrm{hr}$. Although the concentrations chosen are sufficient to block hippocampal LTP at CA1 synapses (Morgan and Teyler, 1999), the involvement of other brain regions and their sensitivity to these antagonists is unknown. We may have simply uncovered the fact that LTP in different regions is sensitive to different antagonists and different concentrations. Subsequent experiments will address this possibility through the use of localized intracerebral drug delivery rather then systemic intraperitoneal injections. Third, assuming that all vdccLTP and nmdaLTP was suppressed, it is possible that this result reveals the existence of a previously unknown form of plasticity.

Given the information we have available to us, we propose that the inability of animals given both drugs to perform on the first trial of each day is explained by postulating that much of the information learned on the previous day is lost after a $21 \mathrm{hr}$ period in which the animals are not exposed to the maze. The decrease in WMEs between trials is because the animals have to, on a daily basis, relearn the procedural rule of not re-entering arms from which they have already eaten and/or have to be able to recreate their spatial map, which is then used on trial 2 to find the baits. The decrease in 
RMEs is because of their relearning, each day, which arms are baited.

One problem with the above possibility is that, on a given trial, across days, these animals seem to show some improvement. The graphs of WMEs and RMEs show a definite decrease in errors on a given trial across days (Figs. 2, 4). Although this trend is clearly visible when focusing on the shaping trials, when the analysis of RME and WME is done only during the acquisition stage, this same group of animals shows only a slight reduction in the number of WMEs and RMEs. This lack of significant change suggests that some learning might be retained across days in animals given both drugs, but this learning might have more to do with becoming comfortable with their environment (implicit learning). This is supported by the fact that RMEs for a given trial are stable across acquisition days. The slight improvement in WME across acquisition days might be explained by postulating that procedural knowledge about entering only one arm is somewhat retained but requires priming to become fully activated. Thus, when both channel types are blocked, it seems valid to claim that once animals have become accustomed to the maze and are eating all the baits, information about which arms are baited seems to be lost over a 21 hr period.

Our data also demonstrate that activation of either NMDA receptors or VDCCs can support the retention of information between days $(<21 \mathrm{hr})$. The group given MK-801 and the group given verapamil alone did not show significantly different WMEs or RMEs between trials 1 and 2, nor did they show any significant increase between trial 2 of one day and trial 1 of the next day. Thus, activation of either of these channels can support retention over a $21 \mathrm{hr}$ period.

Our data on WMEs are in contrast to that published by Shapiro and Caramanos (1990). Their data demonstrate that MK-801 is effective in impairing the acquisition of the radial arm maze task, whereas our animals were able to perform at the same level as the animals given saline. There could be a variety of reasons for this discrepancy. (1) Animals whose hippocampus has been removed tend to perseverate. Because the animals in their experiment were shaped by baiting all the arms, it may be the case that they were unable to unlearn this information. Because our animals were shaped by placing the baits only in the arms that were ultimately to be baited, our animals did not need to relearn which arms were baited. This may explain why they were able to learn the task. (2) We used male rats that, according to the data of Shapiro and O'Connor (1992), are less affected then females by the low dose of MK-801 that we used. Because Shapiro and O'Connor (1992) used female rats, the reduced motor impairment caused by MK-801 in our male animals may have allowed them to be better able to navigate the maze.
In conclusion, these results suggest windows for the requisite activation of NMDA and/or VDCCs in the acquisition of information necessary to perform in the radial arm maze. The storage of information necessary to navigate the maze over a $3 \mathrm{hr}$ delay does not require the activation of either VDCCs or NMDA receptors. A functional VDCC system or a functional NMDA system can support the storage of information for up to $21 \mathrm{hr}$. For information to be retained over a long period ( $>7 \mathrm{~d})$, VDCC activity is required; activation of NMDA receptors is not sufficient to store information over this long of a delay. This finding suggests that the long-held theory that LTMs are stored by a single cascade of events starting with the activation of the NMDA receptor may need to be revisited.

\section{REFERENCES}

Bading H, Ginty DD, Greenberg ME (1993) Regulation of gene expression in hippocampal neurons by distinct calcium signaling pathways. Science 260:181-186.

Bliss TV, Collingridge GL (1993) A synaptic model of memory: long-term potentiation in the hippocampus. Nature 361:31-39.

Caramanos Z, Shapiro ML (1994) Spatial memory and $N$-methyl-Daspartate receptor antagonists APV and MK-801: memory impairments depend on familiarity with the environment, drug dose, and training duration. Behav Neurosci 108:30-43.

Cavus I, Teyler TJ (1996) Two forms of long-term potentiation in area CA1 activate different signal transduction cascades. J Neurophysiol 76:3038-3047.

Fox K, Daw NW (1993) Do NMDA receptors have critical function in visual cortical plasticity? Trends Neurosci 16:116-122.

Ghosh A, Greenberg ME (1995) Calcium signaling in neurons: molecular mechanisms and cellular consequences. Science 268:239-247.

Grover LM (1998) Evidence for postsynaptic induction and expression of NMDA receptor independent LTP. J Neurophysiol 79:1167-1182.

Grover LM, Teyler TJ (1990) Two components of long-term potentiation induced by different patterns of afferent activation. Nature 347:477-479.

Jarrard LE (1993) On the role of the hippocampus in learning and memory in the rat. Behav Neural Biol 60:9-26.

Morgan SL, Teyler TJ (1999) VDCCs and NMDARs underlie two forms of LTP in CA1 hippocampus in vivo. J Neurophysiol 82:736-740.

Olton DS, Papas BC (1979) Spatial memory and hippocampal function. Neuropsychologia 17:669-682.

Shapiro ML, Caramanos Z (1990) NMDA antagonist MK-801 impairs acquisition but not performance of spatial working and reference memory. Psychobiology 18:231-243.

Shapiro ML, O'Connor C (1992) N-methyl-D-aspartate receptor antagonist MK-801 and spatial memory representation: working memory is impaired in an unfamiliar environment but not in a familiar environment. Behav Neurosci 106:604-612.

Shors TJ, Matzel LD (1997) Long-term potentiation: what's learning got to do with it? Behav Brain Sci 20:597-614.

Stricker C, Cowan AI, Redman SJ (1999) Analysis of NMDAindependent long-term potentiation induced at CA3-CA1 synapses in rat hippocampus in vitro. J Physiol (Lond) 520:513-525. 